\title{
Retraction Note to: The effect of gamma-enhancing binaural beats on the control of feature bindings
}

\author{
Lorenza S. Colzato $^{1,2,3} \cdot$ Laura Steenbergen $^{1} \cdot$ Roberta Sellaro $^{1}$
}

Published online: 19 January 2021

๑) Springer-Verlag GmbH Germany, part of Springer Nature 2021

\section{Retraction to: Exp Brain Res (2017) 235:2125-2131 https://doi.org/10.1007/s00221-017-4957-9}

Publisher's Note Springer Nature remains neutral with regard to jurisdictional claims in published maps and institutional affiliations.

The Editors-in-Chief have retracted this original article following an investigation by Universiteit Leiden providing evidence of manipulated data. The investigation concluded that the authors originally tested 88 participants but only data of 40 participants was included in the analysis, without adequate or transparent explanation in the article why participants were excluded from the analysis.

L. Steenbergen and R. Sellaro agree to this retraction, L. Colzato does not agree to this retraction.

The original article can be found online at https://doi.org/10.1007/ s00221-017-4957-9.

\section{Lorenza S. Colzato}

1 Cognitive Psychology Unit and Leiden Institute for Brain and Cognition, Leiden University Institute for Psychological Research, Wassenaarseweg 52, 2333 AK Leiden, The Netherlands

2 Department of Cognitive Psychology, Faculty of Psychology, Institute of Cognitive Neuroscience, Ruhr University Bochum, Bochum, Germany

3 Institute for Sports and Sport Science, University of Kassel, Kassel, Germany 